\title{
Impact of a physical activity program on the anxiety, depression, occupational stress and burnout syndrome of nursing professionals ${ }^{1}$
}

\author{
Anderson Rodrigues Freitas ${ }^{2}$ \\ Estela Cristina Carneseca ${ }^{3}$ \\ Carlos Eduardo Paiva ${ }^{4}$ \\ Bianca Sakamoto Ribeiro Paiva ${ }^{4}$
}

Objective: to assess the effects of a workplace physical activity (WPA) program on levels of anxiety, depression, burnout, occupational stress and self-perception of health and work-related quality of life of a nursing team in a palliative care unit. Methods: the WPA was conducted five days per week, lasting ten minutes, during three consecutive months. Twenty-one nursing professionals were evaluated before and after the intervention, with the Hospital Anxiety and Depression Scale, the Maslch Burnout Inventory, and the Job Stress Scale. The changes in self-perceived health and work-related quality of life were measured using a semi-structured questionnaire. Results: the WPA did not yield significant results on the levels of anxiety, depression, burnout or occupational stress. However, after the intervention, participants reported improved perceptions of bodily pain and feeling of fatigue at work. Conclusion: the WPA did not lead to beneficial effects on occupational stress and psychological variables, but it was well accepted by the nursing professionals, who reported improvement in perceptions of health and work-related quality of life.

Descriptors: Nursing, Team; Burnout, Professional; Motor Activity; Palliative Care; Oncologic Nursing.

\footnotetext{
${ }^{1}$ Paper extracted from master's thesis "The influence of labor gymnastics on the burnout syndrome, anxiety, depression and occupational stress of cancer palliative care nurses" presented to Fundação Pio XII, Barretos, SP, Brazil.

2 MSc, Professional Physical Education, Serviço Especializado em Engenharia de Segurança e em Medicina do Trabalho, Fundação Pio XII, Hospital de Câncer de Barretos, Barretos, SP, Brazil.

${ }^{3}$ MSc, Biostatistics, Núcleo de Apoio ao Pesquisador, Fundação Pio XII, Hospital de Câncer de Barretos, Barretos, SP, Brazil.

${ }^{4}$ PhD, Professor, Programa de Pós-Graduação Stricto Sensu em Oncologia, Hospital de Câncer de Barretos, Fundação Pio XII, Barretos, SP, Brazil.
}

Corresponding Author:

Anderson Rodrigues Freitas

Fundação Pio XII. Hospital de Câncer de Barretos

Instituto de Ensino e Pesquisa

Rua Antenor Duarte Villela, 1331

CEP 14784-400, Barretos, SP, Brazil

E-mail: edufisica.anderson@gmail.com
Copyright $\odot 2014$ Revista Latino-Americana de Enfermagem

This is an Open Access article distributed under the terms of the Creative Commons Attribution Non-Commercial License (CC BY-NC).

This license lets others distribute, remix, tweak, and build upon your work non-commercially, and although their new works must also acknowledge you and be non-commercial, they don't have to license their derivative works on the same terms. 


\section{Introduction}

Nursing professionals working in palliative care (PC) need to face existential and emotional demands, since they are directly exposed to the suffering of patients who are at the end of their lives, and the suffering of their family caregivers(1-2). Although still debatable(3), it is possible that these professionals have a higher risk for developing work-related stress ${ }^{(1)}$. Moreover, this stress has been associated with the occurrence of anxiety(4-5), depression $^{(5-6)}$ and burnout(7). In addition, workers diagnosed with major depression had significant productivity loss in comparison with those without depression ${ }^{(8)}$.

We believe that the welfare of professional caregivers is important, so they can provide excellence in patient care. Thus, the search for interventions targeted toward nursing professionals, in an effort to reduce the risk of occupational health problems, is of utmost importance(9). A meta-analysis showed that, among other benefits, occupational physical exercises may be effective in reducing occupational stress ${ }^{(10)}$. However, little is known about the impact of a workplace physical activity (WPA) program in terms of its improving aspects associated with occupational health in nursing professionals working in oncology PC.

Therefore, the aim of this preliminary study was to assess the effects of a compensatory WPA program on the levels of anxiety, depression, burnout, and occupational stress of a nursing staff working in a palliative care unit (PCU).

\section{Methods}

This was a quasi-experimental, pre-post intervention study, whose intervention was an WPA program applied to a PCU nursing staff. The present study was approved by the Research Ethics Committee (protocol 486/2011).

The intervention was conducted by a physical education professional, who only had access to the collected data after the study had been completed. The compensatory WPA was conducted five days/week, lasting ten minutes, during three consecutive months.

A sample size calculation was not performed before the study because all of the palliative care nursing professionals from the Barretos Cancer Hospital were included. Out of the total of 58 nursing professionals, 54 agreed to participate in the program, and signed the Terms of Free and Informed Consent form.
In order to evaluate anxiety and depression, we used the Hospital Anxiety and Depression Scale (HADS). Cases with values $\geq 8$ were considered positive ${ }^{(11)}$.

For the evaluation of burnout, we used the Maslach Burnout Inventory $(\mathrm{MBI})^{(12)}$, which identifies the syndrome levels within its three dimensions: "emotional exhaustion", "depersonalization", and "personal accomplishment". Each dimension is rated as low moderate or high(13).

Occupational stress was assessed with the Job Stress Scale (JSS) ${ }^{(14)}$, which assesses stress from three dimensions: "psychological demands", "control", and "social support". The combination between "psychological demands" and "control" was assessed according to the Karasek model(15). According to this model, the participants were classified as follows: high strain (high demand/low control); low strain (high control/low demand); active work (high demand/high control); and, passive work (low control/low demand).

A semi-structured questionnaire was used to assess individual perceptions of changes in health and overall quality of life (QoL) as a result of the WPA. This instrument was used to assess the willingness to engage in activities at work and outside of work, concern with their own health, perceived improvement in $\mathrm{QoL}$, and perception of change in symptoms of fatigue and pain.

The HADS, MBI, JSS, and perception of change questionnaire (POCQ) were administered by a research nurse, before and after the intervention.

The Cronbach's alpha was used to measure the questionnaire's internal consistency reliability. We considered values between 0.5 and 0.7 as acceptable and values $\geq 0.7$ as good ${ }^{(16)}$. All domains had Cronbach's alpha values higher than 0.7, except for burnout/ depersonalization ( $\alpha=0.52$ ), occupational stress/demand $(\alpha=0.68)$, and occupational stress/control $(\alpha=0.42)$.

In order to get a more homogeneous sample, we excluded nursing professionals who took paid vacation, took medical leave, and/or had their labor contract terminated during the period of intervention. Moreover, we included only those who had been developing activities at the PCU for $\geq 1$ year. Professionals whose attained a weekly average of $<2$ days of classes were excluded from statistical analyzes. Thus, out of the 54 included in the study, only 21 had their data analyzed.

The proportions of the job stress and burnout categories, as well as the proportion of cases classified as depression and anxiety, were compared before and after the WPA by performing the McNemar's test. We used the Statistical Program for the Social Sciences 
(SPSS), version 19.0 (SPSS Inc., Chicago, IL, USA) and R Statistical Software for all data analyses. A p-value $<0.05$ was considered to be statistically significant.

\section{Results}

Out of the 21 nursing professionals whose data were analyzed, 19 (90.5\%) and two (9.5\%) were assistants/ technicians and registered nurses, respectively. None of the participants were working a second job.

The mean (standard deviation [SD]) age was 37.4 (9.1) years, where 20 (95.2\%) were women, 12 $(57.1 \%)$ had stable marriages, $16(76.2 \%)$ had children, and $15(71.5 \%)$ reported having a family income of $\leq 4$ minimum wages. The mean (SD) time spent training as a nursing professional and years of work in the PCU were 6.8 (2.5) and 9.3 (3.4) years, respectively.

At the beginning of the intervention, eight (38.1\%) participants were classified as anxious, and after the intervention, five $(23.8 \%)$ remained in this same category $(p=0.18)$. Regarding depression, despite a decrease in the number of positive cases, the difference did not reach statistical significance $(n=7, \quad$ [33.3\%] versus $n=3,[14.3 \%], p=0.10$ ) (data not shown).

At baseline, seven (33.3\%) nursing professionals had high levels of "emotional exhaustion" and ten (47.6\%) had levels of "depersonalization". On the other hand, only three (14.3\%) demonstrated low "professional achievement" at work. There was no statistically significant difference in the dimensions of burnout compared to pre- and post- intervention. We should emphasize the high levels of "depersonalization", both pre- and post- intervention (Table 1 ).

Before intervention, $12 \quad(57.1 \%)$ nursing professionals had "low demand", 12 (57.1\%) had "low control", and 12 (57.1\%) had "low social support". After intervention, no statistically significant changes were observed on the variables of occupational stress, but of note is the "low control" shown both before and after the intervention (Table 1).

The relationships between the demand-control dimensions were also compared before and after the intervention. No significant differences were observed between the two moments (Table 2).

Eighteen $(85.7 \%)$ nursing professionals reported improvement in overall QoL, 17 (80.9\%) reported increased attention to their own health, 15 (71.4\%) reported increased eagerness to work, and 12 (57.1\%) noted increased willingness to engage in non-work related activities. Furthermore, out of the 17 participants who complained of fatigue prior to the intervention, ten $(62.5 \%)$ reported an improvement after the intervention. Regarding bodily pain, 20 (95.2\%) reported improvement (data not shown).

Table 1 - Assessment of burnout and occupational stress levels, before and after the workplace physical activity program, Barretos, SP, Brazil, 2011

\begin{tabular}{|c|c|c|c|}
\hline \multirow{2}{*}{ Scores } & Pre & Post & \multirow{2}{*}{ p-value* } \\
\hline & n (\%) & n (\%) & \\
\hline \multicolumn{4}{|l|}{ Burnout } \\
\hline Emotional exhaustion & & & 0.61 \\
\hline Low & $7(33.3)$ & $7(33.3)$ & \\
\hline Moderate & $7(33.3)$ & $10(47.6)$ & \\
\hline High & $7(33.3)$ & $4(19.0)$ & \\
\hline Depersonalization & & & 0.88 \\
\hline Low & $3(14.3)$ & $4(19.0)$ & \\
\hline Moderate & $8(38.1)$ & $6(28.6)$ & \\
\hline High & $10(47.6)$ & $11(52.4)$ & \\
\hline Personal accomplishment & & & 0.54 \\
\hline Low & $3(14.3)$ & $1(4.8)$ & \\
\hline Moderate & $6(28.6)$ & $7(33.3)$ & \\
\hline High & $12(57.1)$ & $13(61.9)$ & \\
\hline \multicolumn{4}{|l|}{ Occupational stress } \\
\hline Demand & & & 0.65 \\
\hline Low & $12(57.1)$ & $11(52.4)$ & \\
\hline High & $9(42.9)$ & $10(47.6)$ & \\
\hline Control & & & 0.48 \\
\hline Low & $12(57.1)$ & $10(47.6)$ & \\
\hline High & $9(42.9)$ & $11(52.4)$ & \\
\hline Social Support & & & 0.18 \\
\hline Low & $12(57.1)$ & $15(71.4)$ & \\
\hline High & $9(42.9)$ & $6(28.6)$ & \\
\hline
\end{tabular}

*Significance value $<0.05$

Table 2 - Comparison of the demand-control relationship, before and after the workplace physical activity program, Barretos, SP, Brazil, 2011

\begin{tabular}{lccc}
\hline \multirow{2}{*}{ Scores } & Pre & Post & \multirow{2}{*}{ p-value* } \\
\cline { 2 - 3 } & $\mathbf{N}(\%)$ & $\mathbf{N}(\%)$ & \\
\hline Demand-Control & & & 0.32 \\
High strain & $4(19.0)$ & $5(23.8)$ & \\
Low strain & $6(28.6)$ & $6(28.6)$ & \\
Active work & 0 & $5(23.8)$ & \\
Passive work & $11(52.4)$ & $5(23.8)$ & \\
\hline *Significance value $<0.05$ & & &
\end{tabular}

\section{Discussion}

In the present study, the WPA was not able to improve the level of mood disorders, burnout or occupational stress. On the other hand, participants 
reported improvement in several important aspects of occupational health, such as working capacity, overall QoL, and some physical symptoms.

Mood disorders in nurses may be associated with work overload, limited technical skills, conflict management, lack of social support at work, and cognitive inability to solve problems ${ }^{(17)}$. The diagnosis of depression was associated with the occurrence of burnout, especially with emotional exhaustion ${ }^{(3)}$. Approximately one-third of the nursing staff had symptoms of anxiety or depression at baseline. Although there was a decrease in the percentage of respondents with anxiety and depression after the WPA, the difference did not reach statistical significance.

Regarding the assessment of occupational stress, we observed no statistically significant decrease in the percentage of emotional exhaustion after the intervention. It is possible that the WPA had some benefit for improving emotional exhaustion, as observed with anxiety and depression. However, the high percentage of professionals with low social support, especially in the second assessment, was striking. It is hard to imagine any benefit from WPA on these aspects, which are closely related to the profile of the professional and the type of nursing management, and also with interpersonal factors. Of the 21 professionals analyzed, $19(90 \%)$ were technicians or nursing assistants, who probably had less autonomy over their work activities.

In the present study, we identified high levels of depersonalization in the nursing team. Depersonalization can be understood as the development of cynicism and insensitivity to one another, and may be a reflection of emotional exhaustion(18). It may also be the result of an adaptative resource employed by staff in an attempt to offset the burden placed on them ${ }^{(18)}$. Moreover, the occurrence of depersonalization was associated with subsequent abandonment of employment in a previously published study(19).

Some nursing interventions present a variety of ergonomic factors which predispose professionals to the development of chronic pain ${ }^{(20)}$. The physical handling of the patient and the administration of repetitive techniques, associated with improper body posture, are relevant precipitating factors(21). Fatigue, a symptom inherent to any work activity associated with high labor demand, is often reported by people with burnout(22). Thus, the improvement on pain and fatigue perceived by participants after the intervention, in addition to a better working capacity and overall QoL, emerged as potential benefits of WPA.
The present study had several limitations. One of them was the small sample size. Moreover, the lack of randomization or a control group (without WPA) made it hard to analyze the results, since many of the conditions related to work or to staff may be present and interacting with one another. Another limitation of the study was the lack of standardized instruments used for the assessment of pain, fatigue and QoL. Nevertheless, the percentage of improvement reported by professionals suggested that the perceived benefit was real.

\section{Conclusions}

The WPA program employed showed no significant effects on mood disorders, burnout or occupational stress. On the other hand, improvement in the control of pain, fatigue, overall QoL, and work ability suggested that new studies employing compensatory WPA must be conducted.

\section{Acknowledgments}

The authors would like to thank the Learning and Research Institute of Barretos Cancer Hospital for revising the English text. Also, they would like to thank the Researcher Support Center of Barretos Cancer Hospital for its help in data collection.

\section{References}

1. Oflaz F, Arslan F, Uzun S, Ustunsoz A, Yilmazkol E, Unlu E. A survey of emotional difficulties of nurses who care for oncology patients. Psychol Rep. 2010 Feb;106(1):119-30.

2. Peters L, Cant R, Sellick K, O'Connor M, Lee S, Burney $S$, et al. Is work stress in palliative care nurses a cause for concern? A literature review. Int J Palliat Nurs. 2012 Nov; 18(11):561-7.

3. Ostacoli $L$, Cavallo $M$, Zuffranieri $M$, Negro $M$, Sguazzotti E, Picci RL, et al. Comparison of experienced burnout symptoms in specialist oncology nurses working in hospital oncology units or in hospices. Palliat Support Care. 2010 Dec;8(4):427-32.

4. Gao YQ, Pan BC, Sun W, Wu H, Wang JN, Wang L. Anxiety symptoms among Chinese nurses and the associated factors: a cross sectional study. BMC Psychiatry. 2012;12:141.

5. de Boer J, Lok A, Van't Verlaat E, Duivenvoorden $H J$, Bakker AB, Smit BJ. Work-related critical incidents in hospital-based health care providers and the risk of 
post-traumatic stress symptoms, anxiety, and depression: a meta-analysis. Soc Sci Med. 2011 Jul;73(2):316-26.

6. Lin HS, Probst JC, Hsu YC. Depression among female psychiatric nurses in southern Taiwan: main and moderating effects of job stress, coping behaviour and social support. J Clin Nurs. 2010 Aug;19(15-16):2342-54. 7. Pereira SM, Fonseca AM, Carvalho AS. Burnout in palliative care: a systematic review. Nurs Ethics. 2011 May;18(3):317-26.

8. Woo JM, Kim W, Hwang TY, Frick KD, Choi BH, Seo $Y$, et al. Impact of depression on work productivity and its improvement after outpatient treatment with antidepressants. Value Health. 2011 Jun;14(4):475-82. 9. Happell B, Dwyer T, Reid-Searl K, Burke KJ, Caperchione CM, Gaskin CJ. Nurses and stress: recognizing causes and seeking solutions. J Nurs Manag. 2013 May;21(4):638-47.

10. Conn VS, Hafdahl AR, Cooper PS, Brown LM, Lusk SL. Meta-analysis of workplace physical activity interventions. Am J Prev Med. 2009 Oct;37(4):330-9.

11. Botega NJ, Bio MR, Zomignani MA, Garcia C Jr, Pereira WA. Mood disorders among inpatients in ambulatory and validation of the anxiety and depression scale HAD. Rev Saúde Pública. 1995 Oct;29(5):355-63.

12. Tamayo RM. Relação entre a síndrome de burnout e os valores organizacionais no pessoal de enfermagem de dois hospitais públicos [Dissertação]. Brasília: Universidade de Brasília; 1997.

13. Laing SS, Hannon PA, Talburt A, Kimpe S, Williams $B$, Harris JR. Increasing evidence-based workplace health promotion best practices in small and low-wage companies, Mason County, Washington, 2009. Prev Chronic Dis. 2012;9:E83.

14. Alves MG, Chor D, Faerstein E, Lopes Cde S, Werneck GL. Short version of the "job stress scale": a Portuguese-language adaptation. Rev Saúde Pública. 2004 Apr;38(2):164-71.

15. Karasek RA. Job Demand, job decision latitude, and mental strain: implications for job redesign. Admin Sci Q. 1979;24:285-308.

16. Streiner LD, Norman GR. Health Measurement Scales: A Practical Guide to Their Development and Use. 4th ed. ed. New York: Oxford University Press; 2008.

17. Wu H, Ge CX, Sun W, Wang JN, Wang L. Depressive symptoms and occupational stress among Chinese female nurses: the mediating effects of social support and rational coping. Res Nurs Health. 2011 Oct;34(5):401-7. 18. Maslach C, Schaufeli WB, Leiter MP. Job burnout. Annu Rev Psychol. 2001;52:397-422.
19. Leiter MP, Maslach C. Nurse turnover: the mediating role of Burnout. J Nurs Manag. 2009 Apr;17(3):331-9. 20. Duarte NS, Mauro MYC. Análise dos fatores de riscos ocupacionais do trabalho de enfermagem sob a ótica dos enfermeiros. Rev Bras Saúde Ocup. 2010; 35(121): 157-67.

21. Holmes MW, Hodder JN, Keir PJ. Continuous assessment of low back loads in long-term care nurses. Ergonomics. 2010 Sep;53(9):1108-16.

22. Danhof-Pont MB, van Veen T, Zitman FG. Biomarkers in Burnout: a systematic review. J Psychosom Res. 2011 Jun; 70(6):505-24. 